\title{
MANAJEMEN ISLAMIC CULTURE MELALUI PEMBIASAAN SHOLAT DHUHA BERJAMAAH DALAM MENINGKATKAN KARAKTER KEDISIPLINAN SISWA
}

\author{
Cindy Mistiningsih \& Eni Fariyatu Fahyuni \\ Universitas Muhammadiyah Sidoarjo \\ cindymist7@gmail.com, eny.fariyatul@umsida.ac.id
}

\begin{abstract}
This paper discusses the management of Islamic Cultur through habituating Dhuha Prayers in Improving Student Discipline. Islamic Cultur is a practice of habituating Islamic values, one of which is the implementation of habituation in congregation. This culture is implemented and familiarized in order to improve student discipline. Prayer is a compulsory worship that must be performed by every Muslim. Prayer services will be able to keep the culprit from the beinous and unjust practices. Prayer is one of the worship services that has disciplinary implications for the culprit. This research belongs to the type of qualitative-descriptive research that is expected to be able to uncover various information with a careful and meaningful description-analysis. Sources of data in this study include the principal, student staff and staff and teachers of Islam. Data collection is done by interview, observation, and documentation. As for the data analysis techniques through the stages of data reduction, data presentation and data analysis. The results of this research are (1) Management of Islamic Cultur beld through habituation of Dhuba Berma'ah (2) Habituation of Dhuba prayer in congregation can improve student discipline.
\end{abstract}

Keywords: Dhuba Prayer and Discipline

\begin{abstract}
Abstrak : Tulisan ini membahas tentang Manajemen Islamic Cultur melalui pembiasaan Sholat Dhuha Berjama'ah dalam Meningkatkan Kedisiplinan siswa. Islamic Cultur adalah merupakan praktek pembiasaan nilai - nilai Islami yang salah satu implementasinya adalah dengan pembiasaan sholat dhuha berjama'ah. Budaya ini dilaksanakan dan dibiasakan dalam rangka meningkatkan kedisiplinan siswa. Sholat merupakan ibadah wajib yang harus dilakukan oleh setiap muslim. Ibadah sholat akan mampu menjauhkan pelakunya dari perbuatan keji dan mungkar. Sholat merupakan salah satu ibadah yang mempunyai implikasi kedisiplinan bagi pelakunya. Penelitian ini termasuk jenis penelitian kualitatif-deskriptif yang diharapkan mampu mengungkap berbagai informasi dengan deskripsi-analisis yang teliti dan penuh makna. Sumber data dalam penelitian ini meliputi kepala sekolah, waka kesiswaan beserta staf dan guru Al-Islam. Pengumpulan data dilakukan dengan wawancara, observasi, dan dokumentasi. Adapaun tehnik analisa datanya melalui tahapan reduksi data, penyajian data dan analisa data. Hasil penelitian diantaranya adalah (1) Manajemen Islamic Cultur diselenggarakan melalui pembiasaan Sholat dhuha Berma'ah (2) Pembiasaan sholat Dhuha berjama’ah dapat Meningkatkan kedisiplinan siswa.
\end{abstract}

Kata Kunci : Sholat Dhuha dan Kedisiplinan

Manazhim : Jurnal Manajemen dan Ilmu Pendidikan

Volume 2, Nomor 2, Agustus 2020; 157-171

https://ejournal.stitpn.ac.id/index.php/manazhim 


\section{PENDAHULUAN}

Pendidikan adalah suatu keniscayaan bagi setiap manusia, education as a necessity of life, demikian menurut filosof progresifisme John Dewey. Artinya bahwa pendidikan merupakan kebutuhan prinsip setiap manusia. atau dengan kata lain bahwa manusia tidak akan dapat dipisahkan atau bahkan tidak akan bisa hidup secara wajar tanpa adanya sebuah proses pendidikan. ${ }^{1}$ Melalui pendidikan manusia dapat mengertitujuan hidupnya dimuka bumi ini. Secara historis, agama merupakan salah satu bentuk legitimasi yang paling efektif. Dalam sebuah perubahan sosial dan transformasi masyarakat yang sedang berlangsung, seperti yang dihadapi Indonesia pada saat ini, perlu diperhatikan mengenai tempat dan peranan, serta fungsi pendidikan dalam membingkai dan mendasari proses perubahan transformasi tersebut, karena sebuah perubahan tidak akan pernah dapat dibendung oleh karena perkembangan budaya atau kebijakan tertentu, melainkan akan berjalan secara alami sesuai dengan perkembangan peradaban manusia. ${ }^{2}$

Pendidikan dalam Islam dipahami sebagai sebuah proses transformasi dan Internalisasi nilai-nilai ajaran Islam terhadap peserta didik, melalui proses pengembangan fitrah, agar memperoleh keseimbangan hidup dalam semua aspeknya. Dengan demikian maka fungsi pendidikan menurut Islam pada hakikatnya adalah proses pewarisan nilai-nilai budaya Islam untuk mengembangkan potensi manusia, dan sekaligus proses produksi nilai-nilai budaya Islam baru sebagai hasil interaksi potensi dengan lingkungan dan konteks zamannya. Kunci keberhasilan umat Islam agar mampu menangkap ruh dan mengimplemntasikan nilai - nilai yang terkandung di dalamnya. Dengan kata lain, tanpa pendidikan manusia tidak akan dapat menjalankan fungsi kemanusiaannya secara baik dan sempurna. Tujuan dan perjalanan hidupnya akan teombang ambing dan tida memiliki pijakan pendidian yang kokoh sehingga mudah dipengaruhi oleh hal - hal yang tidak baik buat kehidupannya.

${ }^{1}$ Mahfud Junaedi, 'Ilmu Pendiddikan Islam: Filsafat Dan Pengembangan' (Semarang: RaSAIL, 2010), p. 85.

2 Muhammad Arif Syaifuddin; Helena Anggreini; Putri Chusnul Khotimah; Choirul Mahfud, 'SEJARAH SOSIAL PENDIDIKAN ISLAM MODERN DI MUHAMMADIYAH', Tadarus: Jurnal Pendidikan Darus Islam, 8 No. 1 (2019). 
Maraknya isu-isu moralitas di kalangan remaja, narkotika dan obat-obat terlarang (narkoba), tawuran pelajar, pornografi hingga prostitusi online yang melibatkan pelajar, menjadi masalah sosial yang sampai saat ini belum dapat ditemukan formula yang tepat untuk mengatasinya. Fenomena ini telah menjadi keprihatinan semua orang dan semua lapisan, baik itu orang tua, sekolah maupun masyarakat dan pemerintah. Bahkan kerusakan yang terjadi tidak hanya pada kualitas manusianya tapi terjadi juga pada kualitas lingkungan hidupnya. Oleh karena itu menjadi sangat urgen untuk membiasakan budaya agama (religius culture) baik dalam kontek kehidupan keluarga maupun sekolah sehingga para generasi muda memiliki kepribadian yang baik. $^{3}$

Pembiasan itu dimaksudkan untuk menginternalisasikan nilai-nilai ajaran agama Islam terhadap pribadi peserta didik sehingga mampu mencerminkan perilaku yang baik, apalagi jika dikaitkan dengan porsi atau jam tatap muka pelajaran agama yang sangat minim. Selain itu juga nilai-nilai ajaran Islam yang ada pada diri anak sering terkalahkan oleh budaya-budaya negatif yang ada di lingkungan sekitarnya. Oleh karena itu perlu adanya penciptaan budaya beragama (religious culture) yang dilakukan secara berkelanjutan dalam proses pembelajaran dengan pembiasaanpembiasaan hidup disiplin, rapi, tertib, bertanggung jawab, ramah, sopan santun, saling tolong menolong, saling menghargai, cinta terhadap lingkungan, taat dalam menjalankan ibadah, membaca Al-Qur'an, dan lain-lain"

Selain sebagai manifestasi komunikasi dengan Allah, shalat juga dapat dijadikan sebagai media untuk memberikan pelajaran tentang disiplin, menghargai waktu, dan teratur dalam menjalani hidup. Shalat mengajarkan tentang kedisiplinan kepada pelakunya, dimana seorang muslim akan melaksanakan shalat sesuai dengan waktu yang telah ditentukan. Jika ia selalu melaksanakan shalat sesuai dengan waktunya, secara tidak langsung ia akan belajar tentang disiplin. Apalagi jika ia istiqomah melaksanakan shalat tepat waktunya maka ia telah menjalani hidup disiplin. Setiap

\footnotetext{
${ }^{3}$ Diah Ningrum, 'Kemerosotan Moral Di Kalangan Remaja: Sebuah Penelitian Mengenai Parenting Styles Dan Pengajaran Adab Diah Ningrum Sekolah Menengah Islam Terpadu (SMIT) Al Marjan', Unisia, XXXVII.82 (2015), 18-30.

${ }_{4}$ Muhammad Arif Syaifuddin and Eni Fariyatul Fahyuni, 'Penguatan Pendidikan Karakter Melalui Kurikulum Muatan Lokal Di SMP Muhammadiyah 2 Taman', PALAPA, 7.2 (2019), 267-85 <https://doi.org/10.36088/palapa.v7i2.358>.
} 
pekerjaan yang biasa dilakukan berulang-ulang maka lambat laun akan menjadi kebiasaan. Orang yang selalu mengerjakan ibadah shalat tepat waktu akan berdisiplin dalam menjalankan kehidupannya karena ia telah belajar dengan tepat waktu.

Menurut Ash Shiddieqy bahwa shalat merupakan ibadah yang istimewa dalam ajaran Islam karena Nabi Muhammad diperintahkan Allah secara langsung pada waktu Isra' Mieeraj. Nasr menambahkan bahwa ritus utama dalam Islam adalah shalat yang akan mengintegrasikan kehidupan manusia ke dalam ruhaniah. Ibadah shalat mempunyai pengaruh yang besar terhadap perilaku, terutama jika melaksanakannya dengan khusyu (bersungguh-sungguh) dan hanya mengharap ridha Allah. Jika manusia melakukannya dengan seperti itu maka perilaku yang sebelumnya negatif akan berubah menjadi positif. Aura yang dipancarkan akan menjadi positif, yang juga akan berakibat pada kehidupan dalam lingkungannya. Segala aktivitas yang dilakukannya akan terasa bahwa ia diawasi dan diperhatikan oleh Allah Swt. Kepribadian yang ada dalam diri seseorang perlu senantiasa dibentuk. Shalat merupakan salah satu cara atau sarana dalam membentuk kepribadian seseorang, yaitu manusia yang bercirikan disiplin, taat waktu, bekerja keras, mencintai kebersihan, senantiasa berkata yang baik, dan membentuk pribadi “Allahu Akbar". Karena shalat adalah kegiatan harian, mingguan, bulanan ataupun tahunan. ${ }^{5}$

Membentuk akhlak yang positif sangat perlu diajarkan kepada anak-anak. Salah satunya memiliki sikap disiplin. Disiplin adalah kunci sukses dan keberhasilan di mata mendatang. Disiplin memiliki makna melatih, mengatur, dan mendidik. ${ }^{6}$ Karena itulah disiplin sangat diperlukan untuk mengajarkan keteraturan dalam hidup. Jika manusia hidup dengan teratur, ia akan mudah meraih kesuksesan. Oleh karena itu penelitian ini dikhususkan untuk mengetahui manajemen implementasi sholat Dhuha dalam meningkatkan kedisiplinan siswa.

\footnotetext{
${ }^{5}$ Subhan Husain Albari, 'Agar Anak Rajin Shalat' (Yogyakarta: Diva Press, 2011), pp. 27-92.

${ }^{6}$ Kediri Tahun Pelajaran, Siti Nor Hayati, and A Latar Belakang, 'KARIMAH SISWA ( Studi Kasus Pada Siswa Kelas XI MAN Purwoasri', Manfaat Sholat Dhuba Dalam Pembentukan Akblakul Kharimah Siswa, 2015, 15-16.
} 


\section{METODE PENELITIAN}

Penelitian ini merupakan penelitian lapangan (field researcb) karena dilaksanakan secara real dan berdasarkan fakta yang ada di lapangan. Jenis penelitian ini adalah penelitian deskriptif-kualitatif. Dengan penelitian ini akan membantu mencermati dan mendeskripsikan data-data sesuai dengan tujuan penelitian ini. Informan dalam penelitian ini adalah bapak Kepala Sekolah, Waka Kurikulum, waka kesiswaan, waka ISMUBA dan guru-guru ISMUBA serta siswa. Penelitian ini digunakan dengan maksud adalah untuk menemukan kenyataan-kenyataan ganda yang terdapat dalam data, membuat hubungan peneliti dengan responden menjadi lebih eksplisit, menguraikan latar secara penuh dan dapat membuat keputusan-keputusan tentang dapat tidaknya kepada suatu latar lainnya, dapat menemukan pengaruh bersama yang mempertajam hubungan-hubungan, dan memperhitungkan nilai-nilai secara eksplisit sebagai bagian dari analitik.

Pengumpulan data dilakukan dengan observasi, wawancara dan dokumentasi yang seterusnya dianalisis dengan cara deskriptif analisis dengan menggunakan metode induktif. Observasi dilakakukan sejak pra-penelitian dan selama proses penelitian berlangsung yang dibantu dengan fieldnote dan observation checklist untuk mengetahui kondisi lingkungan dan kegiatan yang dilakukan dalam mengungkap manajemen implementasi sholat Dhuha dalam Meningkatkan Kedisiplinan siswa. Proses wawancara dilaksanakan dengan cara tatap muka secara langsung antara peneliti dengan informan. Dokumentasi dilaksanakan untuk memperoleh data kebijakan berupa renstra, kurikulum, syllabus, dokumen mutu maupun Rencana Program Sekolah dan juga data lain berupa literature dan catatan yang mendukung penelitian ini.

\section{HASIL DAN PEMBAHASAN}

1. Pembahasan tentang Shalat

a. Pengertian Sholat

Shalat secara bahasa berasal dari bahasa Arab yaitu "asshalatu" yang berarti doa. ${ }^{7}$ Shalat merupakan kata benda yang memiliki arti berarti rahmat, sedangkan shalat dari hamba adalah doa dan permohonan ampunan. Shalat dalam

${ }^{7}$ Mahmud Yunus, 'Kamus Arab-Indonesia’ (Jakarta: PT Hidakarya Agung, 1990), p. 252. 
bahasa Arab juga memiliki arti doa memohon kebajikan dan pujian. ${ }^{8}$ Beberapa pengertian shalat menurut para ahli ilmu agama (fiqih) adalah sebagai berikut:

\begin{tabular}{|c|c|c|}
\hline No & Nama & Uraian / Pendapat \\
\hline 1 & Sayyid Sabiq & $\begin{array}{l}\text { Shalat adalah ibadah yang mencakup ucapan-ucapan } \\
\text { dan perbuatan khusus, dimulai dengan takbiratul ihram } \\
\text { dan diakhiri dengan mengucapkan salam }{ }^{9}\end{array}$ \\
\hline 2 & Ali Asee ad & $\begin{array}{l}\text { Shalat menurut istilah syara }{ }^{\text {ee }} \text { ialah beberapa ucapan } \\
\text { dan perbuatan tertentu yang diawali dengan takbir dan } \\
\text { diakhiri dengan salam }^{10}\end{array}$ \\
\hline 3 & Sulaiman Rasjid & $\begin{array}{l}\text { Shalat ialahibadah yang tersusun dari beberapa } \\
\text { perkataan dan beberapa perbuatan yang dimulai } \\
\text { dengan takbir, disudahi dengan salam, dan memenuhi } \\
\text { beberapa syarat yang ditentukan }{ }^{11}\end{array}$ \\
\hline 4 & $\begin{array}{l}\text { Muhammad } \\
\text { Abdul Malik az } \\
\text { Zaghabi }\end{array}$ & $\begin{array}{l}\text { Shalat adalah tali hubungan yang kuat antara seorang } \\
\text { hamba dengan Tuhan-Nya. Hubungan yang } \\
\text { mencerminkan kehinaan hamba dan keagungan Tuhan } \\
\text { yang bersifat langsung tanpa perantara segala dari siapa } \\
\text { pun }^{12}\end{array}$ \\
\hline
\end{tabular}

Berdasarkan pengertian diatas maka dapat disimpulkan bahwa shalat adalah suatu ibadah yang memiliki hubungan yang kuat antara seorang hamba dengan Allah sehingga hati hanya berharap kepada Allah, mendatangkan takut kepada-Nya, dan mendatangkan rasa keagungan atas kekuasaan-Nya dan kesempurnaan-Nya melalui doa yang disertai ucapan dan perbuatan dengan beberapa syarat telah ditentukan. Shalat memiliki kedudukan yang paling tinggi diantara ibadah yang lain. Tidak ada ibadah apapun yang dapat mengimbanginya.

${ }^{8}$ Muhammad Hasbi Ash Shiddieqy, 'Pedoman Shalat', 2nd edn (Semarang: Pustaka Rizki Putra, 2000), p. 39.

${ }_{9}$ Sayyid Sabiq, 'Ringkasan Fikih Sunnah' (Jakarta: Pustaka Al Kautsar, 2015), p. 58.

${ }^{10}$ Ali As'ad, 'Terjemah Fathul Mu'in 1' (Kudus: Menara, 1980), p. 9.

11 Sulaiman Rasjid, 'Fiqih Islam' (Bandung: Sinar Baru, 1990), p. 64.

12 Muhammad Abdul Malik Az Zaghabi, 'Malang Nian Orang Yang Tidak Shalat' (Jakarta: Pustaka Al Kautsar, 2001), p. 17. 
Agama tidak akan tegak dengan sempurna tanpa adanya shalat karena shalat adalah tiang dari agama.

Macam - macam shalat itu ada 2 yaitu shalat wajib dan shalat sunnah.shalat wajib adalah shalat yang wajib dilakukan oleh setiaporang muslim yang beriman, dewasa dan dalam keadaan sehat serfta tidak berhalangan secara syar'i (perempuan haidl) sedangkan shalat sunnah adalah shalat yang jika dilakukan mendapat pahala dan keutamaan tetapi jika dilakukan tida mengandung resiko dosa atau azab dari Allah SWT. Shalat sunnah seperti shalat tahajjud, shalat Dhuha, shalat sunnah rawatib, shalat istisqa/ shalat istikharah dan sebagainya.

\section{b. Pengertian dan Keistimewaan Shalat Dhuha}

Shalat dhuha adalah shalat sunnah yang dikerjakan pada waktu pagi hari. Waktu shalat dhuha dimulai ketika matahari muncul setinggi matahari tergelincir. ${ }^{13}$ Dalam ketentuan melaksanakan shalat adh-Dhuha juga dijelaskan ketika waktu matahari sepenggalan naik dan demi malam apabila telah sunyi, Allah sangat dekat dengan hamba-Nya dan tidak mau meninggalkannya. Hal ini mengisyaratkan bahwa saat sepenggalan matahari naik, saat itu pula sinyal hidayah Allah memancar dan membuka kesempatan pada hambanya untuk membuka pintu qalbu untuk menerima karunia yang akan diberikan kepada manusia.

Shalat dhuha merupakan salah satu shalat sunnah yang sangat dianjurkan dalam Islam, oleh karena sholat snnah ini memiliki banyak keutamaan, diantaranya adalah sebagai berikut:

\begin{tabular}{lll} 
No & Keistimewaan & \multicolumn{2}{c}{ Uraian } \\
\hline 1 & Penghapus & Dengan bertobat sungguh-sungguh kepada \\
& Dosa & Allah dan berjanji untuk tidak mengulangi \\
& & perbuatan dosa yang sama, maka Allah akan \\
& mengampuni kita. Ada salah satu amalan yang \\
& apabila kita istiqamah menjalankannya, maka \\
& ia bisa menjadi penghapus dosa. Amalan
\end{tabular}

13 Subhan Husain Albari, 'Agar Anak Rajin Shalat (Jogjakarta: DIVA Press, 2011), Hlm. 48' (Yogyakarta: Diva Press, 2011), p. 48. 
tersebut adalah ibadah shalat dhuha. Rasulullah bersabda "Barang siapa menjaga dua rakaat shalat dhuba, maka dosa-dosanya akan diampuni walaupun sebanyak buih di lautan" (H.R. Tirmidzi).

\begin{tabular}{|c|c|}
\hline $\begin{array}{l}\text { Perantara } \\
\text { mengubah } \\
\text { pengalaman } \\
\text { hidup }\end{array}$ & $\begin{array}{l}\text { Shalat dhuha adalah ibadah yang tepat untuk } \\
\text { dijadikan perantara mengubah pengalaman } \\
\text { hidup yang buruk dengan sesuatu yang lebih } \\
\text { baik. Tetapi pastinya dengan diaksikan dengan } \\
\text { bentuk tindakan nyata yaitu dengan } \\
\text { melaksanakan shalat dhuha secara istiqomah }\end{array}$ \\
\hline $\begin{array}{l}\text { Setiap rakaat } \\
\text { shalat dhuha } \\
\text { memiliki } \\
\text { kedudukan } \\
\text { mulia }\end{array}$ & $\begin{array}{l}\text { "Barang siapa shalat dhuba dua rakaat, maka dia } \\
\text { tidak ditulis sebagai orang yang lalai. Barang siapa } \\
\text { yang mengerjakan sebanyak empat rakaat, maka dia } \\
\text { ditulis sebagai orang yang abli ibadah. Barang siapa } \\
\text { yang mengerjakan enam rakaat, maka dia } \\
\text { diselamatkan di hari itu. Barang siapa mengerjakan } \\
\text { delapan rakaat, maka Allah tulis dia sebagai orang } \\
\text { yang taat. Dan barang siapa yang mengerjakan } \\
\text { sebanyak dua belas rakaat, maka Allah akan } \\
\text { membangun sebuah rumah di surga untuknya." (al- } \\
\text { hadits) }{ }^{14}\end{array}$ \\
\hline
\end{tabular}

2. Pembahasan tentang Kedisiplinan

a. Pengertian Kedisiplinan

Kedisiplinan atau disiplin memiliki arti ketaatan (kepatuhan) kepada peraturan. ${ }^{15}$ Dari pengertian tersebut dapat dikatakan bahwa kedisiplinan adalah bentuk kepatuhan seseorang kepada peraturan, baik di dalam sekolah maupun di luar

${ }^{14} \mathrm{Ra} \mathrm{Jab}$, Implementasi Program Shalat Dhuha Dan Shalat Zuhur Berjamaah Dalam Pembentukan Akhlak Siswa (Studi Pada Sekolah Sd Al Hira Permata Nadiah Medan)', ANSIRU PAI : Pengembangan Profesi Guru Pendidikan Agama Islam, 3.2 (2019), 73 <https://doi.org/10.30821/ansiru.v3i2.5851>.

15 Depdiknas, 'Kamus Besar Bahasa Indonesia' (Jakarta: Balai Pustaka, 2005), p. 268. 
sekolah. Jika orang telah bertindak sesuai dengan aturan-aturannya maka ia telah melakukan kedisiplinan. Disiplin juga dapat dimaknai sebagai suatu keadaan dimana sikap, penampilan, dan tingkah laku siswa yang sesuai dengan tatanan nilai, norma, dan ketentuan-ketentuan yang berlaku di sekolah atau dimanapun mereka berada. Kedisipinan dalam sebuah lembaga dapat dijabarkan sebagaisuatu keadaan tertib dimana orang-orang yang tergabung dalam suatu organisasi tunduk pada peraturanperaturan yang telah ada dengan rasa senang hati. Dari pengertian tersebut jika dirumuskan dalam disiplin kelas/sekolah, disiplin kelas/sekolah yaitu keadaan tertib dimana para guru, staf sekolah dan siswa yang tergabung dalam kelas/sekolah, tunduk kepada peraturan-peraturan yang telah ditetapkan dengan senang hati. ${ }^{16}$

Berangkat dari beberapa pengertian diatas maka dapat disimpulkan bahwa disiplin merupakan pokok dasar tiap individu. Kedisiplinan sangat penting dalam kehidupan, karena itulah kedisiplinan harus ditanamkan terhadap individu mulai sejak dini. Jika kedisiplinan ditanamkan terus menerus, maka akan menjadi kebiasaan. Lembaga pendidikan khususnya pendidikan formal merupakan tempat yang sangat berpotensi dalam mengembangkan sikap kedisiplinan.

\section{b. Tujuan Kedisiplinan}

Bagi siswa, kedisiplinan mempunyai pengaruh positif terutama dalam konteks pembinaan kepribadiannya. Kedisiplinan itu akan tumbuh menjadi bekal dimasa yang akan datang. Dengan mempraktekannya dalam kehidupannya, siswa akan dapat mengendalikan diri sehingga kedisiplinan akan terbentuk dengan sendirinya dan melekat dalam prilaku kesehariannya.

Penanaman dan penerapan bahkan pembiasaan sikap disiplin tidak boleh dimunculkan sebagai tindakan pembatasan kebebasan siswa dalam melakukan sebuah tindakan, akan tetapi penerapan disiplin itu adalah sebagai tindakan pengarahan kepada sikap yang bertanggung jawab dan melakukan tindakan yang baik dan teratur dalam kehidupannya. Sehingga dirinya tidak akan merasa bahwa hal itu adalah beban bagi dirinya akan tetapi adalah sebuah kebutuhan.

16 Sri Hartini, 'MODEL KEBIJAKAN DAN PELAKSANAAN KEDISIPLINAN SEBAGAI PEMBENTUKAN KARAKTER SISWA DI MTs NEGERI PRAMBANAN KLATEN', ALAS ASIYYA: Journal Of Basic Education, 1.1 (2017), 108-23 < https://doi.org/10.24269/ajbe.v1i1.460>. 
Tujuan disiplin bukan hanya sekedar membentuk anak untuk mematuhi peraturan yang berlaku, akan tetapi disiplin bertujuan untuk membentuk dan mencetal anak yang bertanggung jawab terhadap dirinya sendiri dan orang lain. Oleh karena itu tujuan kedisiplinan dapat dirumuskan sebagai berikut:

$\begin{array}{ll}\text { No Tujuan } & \text { Uraian } \\ 1 \text { Jangka pendek } & \text { Membuat anak-anak terlatih dan terkontrol, dengan } \\ & \text { mengajarkan pada mereka bentuk-bentuk tingkah } \\ & \text { laku yang pantas atau masih asing bagi mereka } \\ & \text { Mengembangkan pengendalian diri sendiri yaitu } \\ & \text { dalam diri anak itu sendiri tanpa pengaruh dan } \\ & \text { pengendalian diri dari luar. } \\ & \text { Membantu anak didik untuk menjadi matang } \\ & \text { pribadinya dan mengembangkan diri dari sifat-sifat } \\ & \text { ketergantungan menuju ketidak ketergantungan, } \\ & \text { sehingga ia mampu berdiri sendiri di atas tanggung } \\ & \text { jawab sendiri } \\ & \text { Membantu anak mengatasi dan mencegah } \\ & \text { timbulnya masalah disiplin dan berusaha } \\ & \text { menciptakan situasi yang menyenangkan bagi } \\ & \text { kegiatan belajar mengajar dimana mereka mentaati } \\ & \text { peraturan yang ditentukan }{ }^{17}\end{array}$

c. Fungsi Kedisiplinan

Disiplin akan membuat seseorang memiliki kecakapan mengenai cara belajar yang baik, juga merupakan bentuk proses ke arah pembentukan yang baik, yang akan menciptakan suatu pribadi yang luhur. Oleh karena itu fungsi kedisiplinan adalah sebagai berikut:

17 Seto Mulyadi, 'Membantu Anak Balita Mengelola Amarahnya' Jakarta: Gelora Aksara Pratama, 2004), p. 38. 
a) Untuk mengajarkan bahwa perilaku tertentu selalu diikuti hukuman, namun yang lain akan diikuti dengan pujian.

b) Untuk mengajarkan anak suatu tindakan penyesuaian yang wajar, tanpa menuntut suatu konfirmasi yang berlebihan.

c) Untuk membantu anak mengembangkan pengendalian diri dan pengarahan diri sehingga mereka dapat mengembangkan hati nurani untuk membimbing tindakan mereka. ${ }^{18}$

\section{d. Indikator Kedisiplinan}

Untuk mengukur tingkat disiplin siswa diperlukan indikator-indikator mengenai disiplin belajar seperti yang diungkapkan Moenir, indikator-indikator yang dapat digunakan untuk mengukur tingkat disiplin siswa berdasarkan ketentuan disiplin waktu dan disiplin perbuatan. Kriteria disiplin tepat waktu menurut Moenir antara lain:

a) Tepat waktu dalam belajar, mencakup datang dan pulang sekolah tepat waktu, mulai dari selesai belajar di rumak dan di sekolah tepat waktu.

b) Tidak meninggalkan kelas/membolos saat pelajaran

c) Menyelesaikan tugas sesuai waktu yang ditetapkan

Sedangkan disiplin perbuatan, meliputi:

a) Patuh dan tidak menentang peraturan yang berlaku

b) Tidak malas belajar

c) Tidak menyuruh orang lain bekerja demi dirinya

d) Tingkah laku menyenangkan, mencakup tidak mencontek, tidak membuat keributan, dan tidak mengganggu orang lain yang sedang belajar. ${ }^{19}$

e. Unsur - unsur Kedisiplinan

Unsur kedisiplinan yang diambil dari beberapa pendapat dikelompokan menjadi empat anatara lain: pertama adalah peraturan yang dimaknai sebagai pola atau

18 The Liang Gie, 'Cara Belajar Yang Efisien' (Yogyakarta: UGM Press, 1971), p. 59.

${ }^{19}$ Moenir, 'Manajemen Pelayanan Umum Di Indonesia' (Jakarta: Bumi Aksara, 2010), p. 96. 
ketentuan khusus yang ditetapkan secara perorangan atau lembaga tentang suatu yang harus dipatuhi. Menurut Suharsimi bahwa peraturan itu meliputi: perbuatan atau perilaku yang diharuskan dan yang dilarang, akibat atau sanksi yang menjadi tanggung jawab pelaku atau yang melanggar peraturan dan cara dan prosedur untuk menyampaikan peraturan kepada subyek yang dikenai peraturan tersebut. Kedua, hukuman adalah sanksi yang diberikan atau ditimbulkan dengan sengaja oleh seseorang (orang tua, guru, dan sebagainya) sesudah terjadi suatu pelanggaran, kejahatan atau kesulitan. Ketiga adalah penghargaan (Ganjaran), menurut Amir Da'im Indrakusuma bahwa penghargaan atau ganjaran merupakan hadiah terhadap hasil baik dari anak dalam proses pendidikan. oleh karena itu penghargaan adalah merupakan suatu symbol pengakuan akan prestasi yang diraih orang lain dalam hidup dan profesinya. Dan yang terakhir adalah konsistensi sebagai tingkat keseragaman atau stabilitas yang mempunyai nilai mendidik, memotivasi, memperbaiki penghargaan terhadap peraturan dan orang yang berkuasa. Semua unsur-unsur disiplin tersebut setelah disusun dan disetujui hendaknya dijalankan sesuai dengan tata tertib yang ada, karena semuanya itu begian dari alat-alat pendidikan dan berfungsi sebagai alat motivasi belajar siswa ${ }^{20}$

Keempat unsur kedisiplinan tersebut juga dipengaruhi faktor-faktor pendukung untuk mencapai hasil kedisiplinan yang diinginkan yaitu faktor internal dan eksternal. Yang dimaksud dengan faktor internal yaitu adalah faktor yang terdapat dalam diri yang bersangkutan, faktor tersebut meliputi faktor pembawaan pribadi, kesadaran dan motivasi dari setiap individu. Sedangkan faktor pendukung yang lain adalah faktor eskternal yang dipengaruhi dari luar orang bersangkutan seperti keteladanan, nasehat, pembiasaan dan lingkungan.

\section{Implementasi Sholat Dhuha dalam Meningkatkan Kedisiplinan Siswa}

Ibadah dalam Islam tidak semata-mata bertujuan untuk menyembah Allah SW'T, dan mendekatkan diri pada Allah SWT. Menurut para ulama, salah satu ibadah yang sangat penting dalam Islam adalah Shalat. Dengan melaksanakan shalat, seseorang akan mendapatkan energy baru dalam menjalani kehidupannya sebagai

${ }^{20}$ Najmuddin, Fauzi, and Ikhwani, 'Program Kedisiplinan Siswa Di Lingkungan Sekolah: Studi Kasus Di Dayah Terpadu (Boarding School)', Edukasi Islami: Jurnal Pendidikan Islam, 8.2 (2019), 183-206. 
makhluk sosial. Di lain pihak shalat juga dapat mempengaruhi aspek psikologis yakni sebagai pembentukan kepribadian dan menjadi karakter seseorang yang membedakannya dengan yang lainnya, termasuk shalat dhuha. Shalat dhuha adalah ibadah yang dapat dijadikan perantara untuk mengubah pengalaman hidup menjadi lebih baik, yang pastinya dibuktikan secara nyata dengan melaksanakan shalat dhuha secara istiqomah. Shalat dhuha akan menjadi pengalaman hidup yang terbaik jika di awali dengan keyakinan yang penuh bahwa ibadah ini akan bermanfaat untuk meningkatkan dan memperbaiki diri sendiri.

Lembaga pendidikan dapat membentuk kepribadian siswanya dengan mengajak siswa untuk melaksanakan shalat dhuha secara istiqomah di sekolah pada pagi hari sebelum pelajaran di mulai. Karena pada pagi hari pikiran masih belum terisi dengan beban pelajaran yang ada di sekolah. Apabila pikiran siswa fresh setelah melaksanakan shalat dhuha, maka sikap dan pikirannya akan menjadi lebih baik.

Shalat dhuha memiliki rahasia kekuatan yang positif yakni semua sikap, pikiran, dan tindakan akan berubah. Dari yang sebelumnya malas belajar menjadi rajin belajar. Kelebihan dari dampak yang diperoleh setelah melaksnakan shalat dhuha adalah muncul perasaan damai dalam diri sehingga bisa mengendurkan ketegangan otak. Sedangkan kedisiplinan Disiplin dapat diartikan sebagai penataan perilaku, yang dimaksud dengan penataan perilaku yaitu kesetiaan dan kepatuhan seseorang terhadap penataan perilaku yang umumnya dibuat dalam bentuk tata tertib. Menurut Ariosandi, salah satu proses dalam disiplin adalah menerapkan sebuah aturan dan menjaga agar aturan tersebut di penuhi. Disiplin diperlukan oleh siapapun dan dimanapun, begitu pula seorang siswa dia harus disiplin baik dalam mentaati tata tertib sekolah, dalam belajar di sekolah, dalam mengerjakan tugas, maupun disiplin dalam belajar di rumah. Salah satu kunci keberhasilan adalah memiliki sikap disiplin. Jika seseorang memiliki sikap disiplin dalam kehidupannya maka ia dapat memanfaatkan waktu dengan sebaik-baiknya. Disiplin yang tumbuh secara sadar juga akan membentuk sikap, perilaku, dan jalan kehidupan yang teratur dan akan menjadikan siswa sukses di masa mendatang. Dengan membiasakan pelaksanaan shalat dhuha berjama'ah setiap pagi sebelum memulai kegiatan pembelajaran dimungkinkan dapat membantu membentuk pribadi siswa yang memiliki integritas dan jiwa disiplin serta tanggung jawab akan masa depan kehidupannya. 


\section{KESIMPULAN}

Berdasarkan pembahasan di atas maka dapat diambil beberapa kesimpulan bahwa :

1. Pelaksanaan sholat dhuha berjamaah mampu membentuk kepribadian siswa menjadi lebih baik dan bijak serta teratur

2. Pelaksanaan shalat dhuha mampu meningkatkan kedisiplinan siswa dalam melaksanakan tugasnya sebagai pelajar

\section{DAFTAR PUSTAKA}

Ali As'ad, 'Terjemah Fathul Mu'in 1' (Kudus: Menara, 1980), p. 9

Depdiknas, 'Kamus Besar Bahasa Indonesia' (Jakarta: Balai Pustaka, 2005), p. 268

Hartini, Sri, 'MODEL KEBIJAKAN DAN PELAKSANAAN KEDISIPLINAN SEBAGAI PEMBENTUKAN KARAKTER SISWA DI MTs NEGERI PRAMBANAN KLATEN', AL-ASASIYYA: Journal Of Basic Education, 1.1 (2017), 108-23 < https://doi.org/10.24269/ajbe.v1i1.460>

Jab, Ra, 'Implementasi Program Shalat Dhuha Dan Shalat Zuhur Berjamaah Dalam Pembentukan Akhlak Siswa (Studi Pada Sekolah Sd Al Hira Permata Nadiah Medan)', ANSIRU PAI : Pengembangan Profesi Guru Pendidikan Agama Islam, 3.2 (2019), 73 <https://doi.org/10.30821/ansiru.v3i2.5851>

Junaedi, Mahfud, 'Ilmu Pendiddikan Islam: Filsafat Dan Pengembangan' (Semarang: RaSAIL, 2010), p. 85

Moenir, 'Manajemen Pelayanan Umum Di Indonesia' (Jakarta: Bumi Aksara, 2010), p. 96

Muhammad Abdul Malik Az Zaghabi, 'Malang Nian Orang Yang Tidak Shalat' (Jakarta: Pustaka Al Kautsar, 2001), p. 17

Muhammad Arif Syaifuddin; Helena Anggreini; Putri Chusnul Khotimah; Choirul Mahfud, 'SEJARAH SOSIAL PENDIDIKAN ISLAM MODERN DI MUHAMMADIYAH', Tadarus: Jurnal Pendidikan Darus Islam, 8 No. 1 (2019)

Muhammad Arif Syaifuddin, and Eni Fariyatul Fahyuni, 'Penguatan Pendidikan Karakter Melalui Kurikulum Muatan Lokal Di SMP Muhammadiyah 2 Taman', PALAPA, 7.2 (2019), 267-85 < https://doi.org/10.36088/palapa.v7i2.358>

Muhammad Hasbi Ash Shiddieqy, 'Pedoman Shalat', 2nd edn (Semarang: Pustaka Rizki Putra, 2000), p. 39

Mulyadi, Seto, 'Membantu Anak Balita Mengelola Amarahnya' Jakarta: Gelora Aksara Pratama, 2004), p. 38

Najmuddin, Fauzi, and Ikhwani, 'Program Kedisiplinan Siswa Di Lingkungan Sekolah: Studi Kasus Di Dayah Terpadu (Boarding School)', Edukasi Islami: 
Jumal Pendidikan Islam, 8.2 (2019), 183-206

Ningrum, Diah, 'Kemerosotan Moral Di Kalangan Remaja: Sebuah Penelitian Mengenai Parenting Styles Dan Pengajaran Adab Diah Ningrum Sekolah Menengah Islam Terpadu (SMIT) Al Marjan', Unisia, XXXVII.82 (2015), 18-30

Pelajaran, Kediri Tahun, Siti Nor Hayati, and A Latar Belakang, 'KARIMAH SISWA ( Studi Kasus Pada Siswa Kelas XI MAN Purwoasri', Manfaat Sholat Dhuba Dalam Pembentukan Akblakul Kharimah Siswa, 2015, 15-16

Sayyid Sabiq, 'Ringkasan Fikih Sunnah’ (Jakarta: Pustaka Al Kautsar, 2015), p. 58

Subhan Husain Albari, 'Agar Anak Rajin Shalat' (Yogyakarta: Diva Press, 2011), pp. 27-92

—, 'Agar Anak Rajin Shalat (Jogjakarta: DIVA Press, 2011), Hlm. 48' (Yogyakarta: Diva Press, 2011), p. 48

Sulaiman Rasjid, 'Fiqih Islam' (Bandung: Sinar Baru, 1990), p. 64

The Liang Gie, 'Cara Belajar Yang Efisien’ (Yogyakarta: UGM Press, 1971), p. 59

Yunus, Mahmud, 'Kamus Arab-Indonesia' (Jakarta: PT Hidakarya Agung, 1990), p. 252 